\title{
Assessing and Developing Good Labour Practices For Migrant Workers in South Korea
}

\author{
Seongsu CHI \\ Waseda University
}

\begin{abstract}
Over the last fe w decades, South Korea has experienced the sharp decrease of birth rate, the upsurge of ageing population, and the exp ansive education accessibility simultaneously, which led to severe labou $\mathrm{r}$ shortage. Consequently, South Korean government decided to employ migrant workers. After the implementation of immigration policy, a large number of labour migrants migrate $d$ to the $\mathrm{c}$ ountry; however, their policy faced heavy criticism from both academia and human rights organizations for its lack of migrant worker protection. This led to policy revision by the government, which improved on several migrant's work and living conditions. While this revised policy is deemed successful by the government , academia and human rights org anizations still reprimand this policy , especially from $t$ he aspect of human trafficking. Therefore, this study aims to assess South Korean immigration policy obj ectively, by using international human rights standards, focusing on the extent of human rights protection for migrant workers under the current immigration policy. Data, which are applied to assess, are collected from government's immigration policy instr uctions, labour laws, and International Organization for Migration [IOM]; moreover, other data, which are used to comprehend the assessment from scholars, are collected from news articles and journal articles. In conclusion, this study argues that there is the gap between government's immigration policy and their implementation. Apart from supplying analytic insights for South Korean immigration policy makers, findings can also be applied as a reference for other countries which undergo similar policy development process.
\end{abstract}

Keywords: Human rights; Immigration policy; Labour protection; Migrant worker; South Korea 